\title{
Online learning and teacher education: The experiences of Indigenous teacher education students
}

\author{
Alison Reedy \\ Charles Darwin University \\ alison.reedy@cdu.edu.au
}

\section{Heleana Wauchope Gulwa}

Marmaruni School, Minjilang (Croker Island)

heleana.wauchope@ntschools.net

\begin{abstract}
Online learning is an integral component of higher education delivery at Charles Darwin University, a regional university located in the Northern Territory, Australia. This paper draws on data obtained through the conversational method of 'yarning' (Bessarab \& Ng'andu, 2010) with five Indigenous teacher education students about their experiences in online learning at CDU. Analysis of the data revealed their experiences were impacted by issues related to access and mode of study and the advantages of online learning were offset by a sense of isolation when studying fully online. This paper draws from data obtained from a broader Educational Design Research study that explored the experiences of Indigenous higher education students across a range of disciplines and the implications of these experiences for the design of online learning environments.
\end{abstract}

\section{Introduction}

We live in the western world but quality western education is not provided in our communities. Too many Balanda (non-Indigenous) teachers do not understand the issues, the real problems out there. This is why we need Indigenous teachers. (F40)

Access to and equity in higher education in Australia have been marked over the past decade by significant policy initiatives, reviews and recommendations aimed at increasing participation and completion of Indigenous people in higher education (Aboriginal and Torres Strait Islander Higher Education Advisory Council, 2015; Behrendt, et al., 2012; Bradley, et al., 2008). However, while there is a significant focus on and funding of programs that look towards building Indigenous peoples aspirations, participation and success in higher education (Frawley, et al., 2015) there is a long way to go towards achieving parity for Indigenous (Aboriginal and/or Torres Strait Islander) students in higher education (Pechenkina \& Anderson, 2011). While enrolment numbers in higher education are increasing for Indigenous students and the percentage of Indigenous students participating in higher education is increasing as a proportion of overall enrolment (Australian Department of Education and Training, 2015b), Indigenous students are still underrepresented significantly in higher education (Pechenkina \& Anderson, 2011).

Parity of outcome in higher education also remains elusive. Even with increasing participation in higher education, Indigenous students' performance suggests equity for Indigenous students extends beyond the concept of access to higher education (Pechenkina \& Anderson 2011). Completion of higher education courses remains significantly lower for Indigenous students than for higher education students overall (Australian Department of Education and Training, 2015c). An array of initiatives at the federal, as well as institutional levels, have been 
implemented to support Indigenous students to enter into and complete their studies, for example the Higher Education Participation and Partnerships Program (Australian Department of Education and Training, 2015a). Additionally, programs and initiatives have been established to attract Indigenous people into specific disciplinary areas, such as teacher education. These include the Growing Our Own (GOO) program and the Remote Indigenous Teacher Education (RITE) program in the Northern Territory (NT) (Nutton, et al., 2012).

The participation of Indigenous students in higher education is skewed towards the social sciences and caring professions and is predominantly clustered in the fields of society and culture, health and education. Teacher education is clearly an attractive option for Indigenous students, with $15 \%$ of all Indigenous higher education participation being in the field of education (Australian Department of Education and Training, 2015c). Increasing the number of Indigenous people who enrol in teacher education programs and go on to become qualified teachers is strategically important, as having Indigenous teachers in the classroom improves outcomes for Indigenous students. Additionally, Indigenous teachers in mentoring roles provide non-Indigenous teachers with guidance on teaching Indigenous students. This has an impact on the education of Indigenous students, as non-Indigenous teachers in the main "simply do not know enough about how to teach Indigenous children" (Santoro, et al., 2011).

\section{Research Approach}

This paper draws on data obtained from in-depth yarning sessions with five Aboriginal and Torres Straight Islander teacher education students aged 28 to 41 years old about their experiences in online higher education at Charles Darwin University (CDU). Yarning is a culturally appropriate conversational method for working with Indigenous people in the conduct of research (Bessarab, 2012; Bessarab \& Ng'andu, 2010; Kickett, 2011). It provides a respectful frame and pace in which to engage with and listen to stories, with a focus on allowing a narrative to evolve and emerge in its own way and in its own time. These yarning sessions took place between mid 2014 and the end of 2015 in person or by telephone. The students were located in the Northern Territory, Queensland and Victoria.

The data used in this paper was drawn from a larger study that investigated the experience of online learning of Indigenous higher education students from across a range of disciplines at CDU. The study was situated within an Educational Design Research (EDR) framework (Reeves et al., 2005; Reeves \& McKenney, 2012), which provided an approach to addressing practical problems located in the educational setting of CDU. The study involved iterative cycles of investigation and analysis of the online learning environment at CDU, which has the Blackboard Learning Management System (LMS) at its core. The purpose of the study was to develop design principles to guide the creation of online learning environments that support the success of Indigenous students in higher education.

The yarning sessions were transcribed verbatim and were sent back to the participants for confirmation. The transcripts were then thematically coded using the software analysis tool NVivo. For the purposes of this paper, the Indigenous and the non-Indigenous author engaged in the process of "collaborative yarning" (Bessarab \& Ng'andu, 2010) to deepen the analysis of the experiences of the teacher education students who contributed to the study. The concept of collaborative yarning has resonance with Nakata's conceptualisation of the contested space of the "Cultural Interface" (Nakata, 2007a; 2007b). In this study, the authors engaged at the cultural interface through deep listening and reflection to work through contested interpretations of the data and to connect with and to develop a shared understanding of the participants stories and the emergent themes. 


\section{Access and participation: unequal progress}

Charles Darwin University has a strong focus on online learning as a means of educational delivery, with more than $60 \%$ of students enrolled externally. Although the NT has a small population base, CDU's online delivery strategy enables it to attract students from across Australia and is also geared to attract a significant international cohort. With an Indigenous population of over $30 \%$ in the NT, CDU also has a strong focus on attracting local Indigenous people into higher education. Given the online focus of CDU, external online study is a viable means of accessing and participating in studies towards a higher education qualification.

While CDU has a high Indigenous student participation rate of 5.5\% (Charles Darwin University, 2015) relative to $1 \%$ in the higher education sector (Australian Department of Education and Training, 2015d), the success rate for Indigenous students is $20 \%$ below that of all higher education students (Charles Darwin University, 2015). So while there is significant work being done nationally as well as locally at CDU to build aspiration for higher education study (Frawley et al., 2015), there is arguably a greater need to examine and address the issues around the attrition of Indigenous students from their academic studies. In particular, there is a gap in the literature around the experience of Indigenous teacher education students (Bat \& Shore, 2014; Moreton-Robinson, et al., 2012), and of the experiences of Indigenous higher education students in online learning. This paper contributes to filling this gap through exploration of the experiences of five teacher education students of online learning. The implications of their experiences in terms of the design of online learning environments is part of the broader study and is only touched on in this paper.

\section{Pathways into Higher Education}

Indigenous students are more likely than non-Indigenous students to enter into higher education via non-traditional pathways due to lower rates of high school completion and lower achievement of the requirements for direct entry into university from school (Behrendt et al., 2012). Of the five teacher education students in this study, none gained direct entry into university on the basis of their year 12 marks, although two had completed high school. All came into teacher education programs as mature age students via a Vocational Education and Training (VET) pathway or through one of the two tertiary preparation programs offered at CDU, the Indigenous tertiary enabling program Preparation for Tertiary Success (PTS) or the Tertiary Enabling Program (TEP).

I wanted to go to uni when I was in year 12 but then I didn't finish year 12. (F30)

I didn't get my NTCE' because I lost out on two marks I think in my art. And obviously I was out of school for, what was it, seven years. So seven or eight years. So I had to do some sort of course to figure out my score. (F28B)

At the age of thirty I enrolled at Batchelor Institute and began the journey of formal western education. In 2009 I graduated from Batchelor with the Certificates II and III in Spoken and Written English. I then went into the Preparation for Tertiary Studies program (PTS) because my aim was to find out more. My goal was to learn and get further into study, to answer my questions about English and education. (F40)

1. Northern Territory Certificate of Education 
The alternative entry pathways were critical in providing the Indigenous teacher education students in this study with a way into higher education. Without such pathways none of them would have started their teacher education studies.

\section{Ways of doing teacher education: study modes}

In the School of Education at CDU there are multiple study mode options that provide a level of choice and flexibility for Indigenous students entering into teacher education. It is of note, however, that in $2014 \mathbf{8 7 \%}$ of all students in the School of Education were enrolled as external students, studying fully online. While external study is the predominant mode of course enrolment, Indigenous students undertaking undergraduate teacher education have three study mode options. As well as external and internal study modes, which are both online reliant and open to all students, Indigenous students can also opt to enrol in Batchelor mode. Batchelor mode is a mixed-mode approach that combines an intensive workshop of one to two weeks per semester with external online study. This option was provided through the Australian Centre for Indigenous Knowledges and Education (ACIKE), a partnership arrangement between CDU and Batchelor Institute of Indigenous Tertiary Education. The workshops were held mainly at Batchelor campus, south of Darwin or at the Desert People's Centre in Alice Springs.

Additionally, in some remote and very remote Indigenous communities in the NT, community work-based teacher training initiatives provide Indigenous people with a way of accessing teacher education programs within their communities. Programs such as Catholic Education's Growing OurOwn (GOO) and the now defunct NT Department of Education's Remote Indigenous Teacher Education (RITE) are two such programs that were set up in remote community schools to provide opportunities for Indigenous people to gain teaching qualifications within their communities and while working concurrently in the local school with a mentor teacher (Nutton et al., 2012; Reedy, et al., 2011). This apprenticeship model was established to benefit the individuals, the schools and the communities they serve through the development of an educated and skilled teaching workforce in remote and very remote areas ${ }^{2}$.

Work-based teacher education programs such as GOO and RITE have significant delivery costs and by their nature have low numbers of students (Nutton et al., 2012). They provide a fast paced work-integrated approach to teacher education with course delivery in condensed timeframes. In the now discontinued RITE program, higher education studies took place two days of the week with the student teachers working in the classroom the other three days. The RITE program had two cohorts of students; the first cohort of seven students ran in 20102012, however, the program was defunded prior to any of the second cohort of students completing the course.

\section{Choosing modes}

As indicated in the previous section, Indigenous teacher education students at CDU have three modes in which they can enrol in teacher education studies, as well as the work-based teacher education programs offered in selected communities. In this study, all students had clear preferences for their mode of study. For one student, the teacher education training became a possibility when the RITE program was offered in her community. The four other students chose to study in Batchelor mode. The extracts below demonstrate the importance of delivery mode in the students' decisions to commence their teacher education training. 
I didn't want to do the first year in mainstream. I don't know if that's the right terminology. I apologise if that's incorrect terminology. But I didn't want to do it through the mainstream programming. I wanted to stay with ACIKE; I just like the format of what ACIKE delivers. (F31)

The Learning on Country program in Maningrida needed an Indigenous person to pilot the program with the rangers and the school. So I took up that position. It was while I was working with the school on this program that I was approached by the headmaster and offered an assistant teacher position at the school. I was also offered a position in the Remote Indigenous Teacher Education (RITE) community based teacher education program because the principal and the school could see the potential in me. They could see what I could deliver, that I could give my skills, and they knew I would gain skills with a quality education and a teaching degree. The RITE program became available to me, it was offered in the community, and it was the right place and the right time for me to question myself and to take up the opportunity because I knew I wasn't going to stop with my education. I wanted to become a teacher to share the knowledge I have gained in this past journey of my life. (F40)

While all study modes offered by CDU require students to engage with CDU's online learning environment, external online study with no face-to-face contact at all with the lecturer or other students was not the preferred mode of enrolment for any of the students. Regardless of this, four of the five teacher education students had enrolled in some of their units in external mode at the time the yarning sessions took place. One other student expected to enrol in online units in order to complete course requirements. The multiple options of study modality appear at one level to provide choice and flexibility to students; however, the full range of study modes is not always available in all units. Indeed, studying units in external mode was a choice made out of necessity rather than preference for all students in this study.

I've been lucky so far and all of mine are workshop mode. I haven't had to pick an external one yet, but I know that option is available if the workshop ones aren't of interest I can choose the other mode. That's my first preference and like I said, that's the reason why I chose to do the higher education in teaching, is because I liked the set up of the ACIKE workshop mode. (F31)

One of the teacher education students in this study commenced in the Remote Indigenous Teacher Education (RITE) program and continued as an external student studying fully online when that program was defunded. Her 'choice' of study modes was restricted to external study.

But then the NT government scrapped the [RITE] program within two years. We managed to continue. So the first group completed. I was in the second group and we were left hanging. So I asked 'Where to next? What does the future hold for my education? Where and how can I complete it?' The big step was to complete the teacher education program remotely and online. So I transitioned into an online student to complete the degree. (F40)

All teacher education students at CDU experience the online learning environment through the Learning Management System (LMS) known as Learnline. Course materials, activities and assessment are located in the LMS regardless of the mode of a student's enrolment. Yet 
accessing readings or submitting an assessment through an online portal while engaging in face-to-face study through the ACIKE model or in the RITE program was a very different experience to studying a unit fully online and one that most wanted to avoid if possible.

\section{Internet access: online learning where access is limited}

While all of the students in the sample indicated they were proficient users of computer technology and all owned their own laptops, they embraced online study with different attitudes and approaches.

I love technology. Like I said I got a new phone today because my screen was cracked. And so l've got the latest gadgets, you know? I've got the iPad. I've got the Samsung note. You know, I love technology. I just think there's a place and time for it. I think as educators we're relying too much on... technology for higher education. (F30)

In some instances, internet access was a factor limiting participation in external online study. This aligns with research that shows home internet access is lower for Indigenous people than other Australians and there are uneven patterns of internet access in remote Indigenous communities (Rennie et al 2015). This uneven pattern is linked to availability of mobile broadband services. Where internet is not available or reliable this results in "digital exclusion" (Rennie et al., p. 3) for the people of those communities. Problematic access to the internet caused intense frustration and anxiety in a number of the students in this study.

The weaknesses of studying online were that the weather would close down the internet access. Rats, ants and fires would close down the internet. Burning off would damage the cables. Internet access was shut down on a daily basis in the dry season and wet season. (F40)

Thursday Island is kind of a main island of the Strait, so their signal can be very good but ours can be dropping and now that we've got lots of trawlers and ships come in like to the island, they do prawning and stuff around here. They've got this boost. When they turn it on it just cuts our signal. Yeah. Just, that's why it's so frustrating. [...] whenever there's ships going in, going by, it just affects the signal. Not only computer signal. Phone signal. Yeah we can't really do anything. It's like going back to the past. (F41)

I can read something on Learnline and then it will freeze. And it can freeze for a couple of hours and then come back, or it can freeze and stay like that, down for like two days, and then if I have stuff to post online, I can't do it there and then. (F41)

While access to the internet is a prerequisite for online study, the student experience of the online environment was far more complex than just about gaining access to this environment and having the necessary technology skills to engage within it. Even those students located in very remote communities in the Torres Strait and in the Northern Territory were able to get online although not necessarily in time frames that matched the task or assessment requirements of their units. Furthermore, the cost of access was an impediment for some students going online. 
Financially I'm struggling... We're living in a very high cost of living. Internet cost is very high. (F41)

Thus, learning design considerations have important ramifications for the engagement of students with limited or intermittent internet access and for students for whom internet access may be prohibitively expensive. For example, students noted particular difficulties with activities that required synchronous involvement or online collaboration. In one instance, a student noted the length of time it took for a task to be completed due to students living in remote areas having to find windows of opportunity to go online and pass their part of the assignment on to others. In another instance the same student noted feeling excluded from an online group task due to her inability to communicate within prescribed time frames.

So, I find myself I drifted a couple of days behind but I told it up there (on the online discussion board) because l've already done the readings and research and stuff (F41)

The issue of uneven and intermittent internet access is beyond the sphere of influence of the academic staff working with Indigenous students in remote communities in the cases cited. However, the design of the learning environment is within the control of academic staff and impacts significantly on the experience of students studying online.

[Learnline] is really bad. I can't find the wording for what I'm trying to say. I don't think it's utilised, like from the lecturer's point of view in setting it up and stuff like that. I don't think that the tools that should be there are utilised as well as what they should be and set out as well as what they should be. (F30)

Learning design considerations such as providing options for how students can engage in activities and providing resources that can be easily downloaded and accessed offline can make a difference to student engagement and progression. Additionally, flexible or negotiated timeframes for task completion would assist students who had limited or unreliable access to the internet.

\section{The benefits of online learning}

The students in the study had varied and at times contradictory experiences in the online environment. Although external online study was not the first choice of any of the students, they were all able to appreciate the benefits of the online environment at different times and for particular purposes. These benefits included being able to stay at home and study, as well as to communicate and share ideas with a range of people in the online environment.

I didn't find it hard to work online, like on Learnline. I've enjoyed it. I loved to do it that way because of still staying with the family and you know, studied from home, online. But it's the signal. We can't work or do things online because of where we are, very remote, very isolated. (F41)

[I like] the posting stuff. You're exchanging ideas. Like you're reading what other people, other students, are saying and you're answering to it like you're giving your, what you're thinking, what your ideas about it. Like you're thinking something different and you're actually reading there and then what other people are posting. I do like that because you're exchanging and you're giving at the same time. (F41) 
For the student enrolled in the RITE program, the transition into external study provided some unexpected benefits. The change in study mode allowed the student to become more autonomous and take more control over her study. This was a distinct change from the highly charged and intensive nature of the RITE program.

After that year I was on my own. As an adult I faced the challenge of having to understand what learning looks like and sounds like without having a lecturer or a tutor right there to support me and I learned how to become an independent learner online. (F40)

Online, even though I had deadlines I could ask if I could have a week more to complete it. I felt like I was at ease, more in control of my studies and I could get online and talk to someone if I wanted. That's one thing I noticed that was easier for me when I didn't have a lecturer down my throat. The strength of studying online was knowing that the resources were available for learning on the computer and internet. (F40)

\section{Concerns about online learning}

Studying externally online requires students to be autonomous learners and to have a strong understanding of academic expectations. Without a knowledge of the higher education environment some students felt very unsure of themselves and of what they were expected to do and consequently floundered. Some students were confused about where to start in the online environment and felt the online environment was alien to then. The lack of clarity of expectations was compounded for students with language backgrounds other than English who struggled to interpret written statements without redress to verbal clarification.

[When] a lecturer puts up a post and then I read it, I, like I said before, English is my second language, so I probably look at it differently, you know what I mean? Like I'm not sure about where it's going and about [what] he or she is really asking, what the question is really focusing on. (F41)

It was all face-to-face until the last three units online. I didn't have that online experience before and I'm, honestly, I don't know where to start when I was online, what to do. (F41)

The timeframes and nature of synchronous online sessions were also an issue for students, particularly where the student was located in a different time zone to the lecturer. Faulty cameras and lack of engagement led one student to express that synchronous online interaction "just feels a little bit robotic". (F31)

Overwhelmingly the students expressed a preference for learning in a social context in a faceto-face environment.

One of my units this semester was only offered externally so I had to do it externally. Mostly I try and get into Batchelor workshop mode because it's very difficult externally. I'm not one to sit in front of a computer for ten hours a day, for ten hours each unit. And that's basically what they expect you to do with Learnline. (F28B) 
It's much better in the workshop mode. It's better in a classroom setting because you get that student interaction and that teacher interaction. We can get feedback then and there where as with Learnline we have to sit on it for days till someone gets back to you. (F28B)

The thing I love about ACIKE and being able to go to Batchelor and have these internal units is because I get that face-to-face with my peers. And I get to know them really well and I get to learn off them. You know the discussion board is not the same. (F30)

The irony of the online environment is while it has the technological affordances that invite networking and interaction, in the main the students in the sample found online interaction to be isolating.

It's just I just feel like I'm left out. I don't know why but it's just I feel like I'm in the corner. It's different. I guess I'm so used to being in a group face-to-face with my lecturer and other students and I feel isolated because I don't know who I'm talking to and, you know, I don't know where they are. (F41)

The issue of isolation in the learning environment was exacerbated when students were located in geographically remote or very remote areas and were also experiencing isolation due to their physical location. In particular, students were isolated from services and supports that enable the use of digital technologies.

I'm in the Torres Strait, a little island. It just looks like, yeah, it don't have big shops that I can walk in with my laptop and get it fixed and you know, it's just one little shop and that's it, one little council building. (F41)

I've got a printer at home but it's run out of ink. Its money, and you can't get ink on the island. So you have to contact family in Cairns or Thursday Island (to see) if they can; send them the money; they get it. It's a very long process. (F41)

\section{Online learning and connection}

In comparison to the online learning environment, the teacher education students in the sample found their identities as Aboriginal or Torres Strait Islander peoples was acknowledged in the workshop and in the community teacher education program. Their shared experience of being Indigenous helped to forge deeper connections.

There's a level of trust and kind of connectivity. I guess maybe your culture and stuff kind of gives you that common ground. (F31)

In the RITE program, students already knew each other and the shared struggles as well as triumphs experienced during the program strengthened these bonds.

It was very intense. I devoted me, and the other girls we all devoted our life to it. I was always doing it. If I'd go out, l'd get so stressed, and would be tired, withdrawn and in tears. A whole lot of us would just be in tears and the stress wasn't healthy. We'd all go over together to see the doctor to monitor our health. We'd go as a 
team, as a family little group. Even though we were all family we come as a little teacher group, a group of Indigenous teachers. We all supported each other and we looked after each other. (F40)

Similarly students studying in the workshop mode found they developed strong bonds through the intensity of their contact. Their friendships with other students enrolled in teacher education, as well as with students in other disciples, developed and continued through social media outside of the workshop weeks.

We all dorm together, like you become that little bit closer like the friendships that you make and the bonds that you make are pretty, a lot stronger because it's amplified because you're with that person 24/7. (F31)

The experience of external study on the other hand was isolating and left students feeling that they were the only Indigenous student in the (virtual) class. The students felt they had no means of finding out if there were other Indigenous students enrolled in their units and making a connection with them.

Yet, regardless of a preference for a face-to-face learning context, external online study had been, or was anticipated to be, the reality for all of the students in the sample at some point in their teacher education course. Additionally, all were involved through the Learning Management System (LMS) in the online learning environment regardless of whether they were enrolled in a unit externally or not. Many found the LMS inherently clunky compared to their use of social media and it was not conducive to building connections with other students.

And you know you text message a person and it's an instant reply. They get an instant notification. Well not an instant reply but they get a notification that there's a text message waiting there for them. Whereas in the discussion board you have to remember to go on and check them because there's no email that says there's a notification, or that someone's replied to this post that you've replied to or whatever. (F30)

As a result of this clunkiness some students engaged in the LMS as little as possible.

One student had a high level of ambivalence towards the online environment and regretted this at the end of semester after sitting the final exam and contemplating failing the subject.

I'm kind of disappointed in myself now because I'm like I wish now I'd I used (the Learnline environment) more in case. I honestly don't even know if that information was in there. (F31)

\section{Conclusion}

Online external study is the main mode of delivery of teacher education at CDU, yet it is not the preferred mode of study for the students who participated in the research described in this paper. To a large extent, the Indigenous teacher education students appreciated the benefits of online learning when it was part of mixed-mode delivery but were increasingly forced into external study, which contributed to a sense of isolation from their peers and lecturers. Their overwhelmingly preference for mixed-mode study was due to an appreciation of the benefits of online learning while balancing this against the frustrations of online learning such as those caused by poor internet access and the confusion and isolation of studying fully online. 
The students' experiences of online learning were negatively impacted when their preferred mode of study was removed. This occurred when the Batchelor mode was not offered, or the defunding of the RITE program which left one student with external study as the only realistic option to complete her course. Consideration of student preferences of study mode is therefore an important factor in terms of enhancing the experience of Indigenous teacher education students in higher education. Additionally, enhancing the design of online learning environments would improve the overall experience of Indigenous students engaged in online learning at CDU given the LMS is a ubiquitous component of learner engagement at CDU, regardless of study mode. To that end, further research is being conducted as part of the broader study described to inform an evidence-based approach to online learning design at CDU. Yarning with Indigenous teacher education students and drawing on their experiences of online learning, as well as making sense of this data through collaborative yarning in a cross-cultural environment is critical to achieving that end.

\section{References}

Aboriginal and Torres Strait Islander Higher Education Advisory Council. (2015). ATSIHEAC recommendations: accelerating the pace of change in Indigenous higher education. Retrieved from https://docs.education.gov.au/node/39006.

Australian Department of Education and Training. (2015a). Higher Education Participation and Partnership Program (HEPPP). Retrieved from https://www.education.gov.au/ higher-education-participation-and-partnerships-programme-heppp

Australian Department of Education and Training. (2015b). Selected Higher Education Statistics 2013 Student Data: 2013 Indigenous Students Retrieved from https://docs.education.gov.au/ node/35969

Australian Department of Education and Training. (2015c). Selected Higher Education Statistics - 2013 Student Data: Appendix 5 Equity Performance Data. Retrieved 15 November 2015 https://docs. education.gov.au/node/36589

Australian Department of Education and Training. (2015d). Selected Higher Education Statistics - 2013 Student Data: Attachment B Summary of the 2013 full year higher education student statistics. Retrieved 21 November 2015 https://docs.education.gov.au/node/35955

Bat, M., \& Shore, S. (2014). More Aboriginal and Torres Strait Islander Teachers Initiative. Listening differently: an exploration fo grey literature about Aborigianl teacher education in Top End of the Northern Territory. Retrieved from Darwin

Behrendt, L., Larkin, S., Griew, R., \& Kelly, P. (2012). Review of Higher Education Access and Outcomes for Aboriginal and Torres Strait Islander People: Final Report. Retrieved from Canberra:

Bessarab, D. (2012, 31 July ). Yarning - A Culturally safe method of Indigenous conversation. Paper presented at the Dementia Networking Seminar Curtin University.

Bessarab, D., \& Ng'andu, B. (2010). Yarning About Yarning as a Legitimate Method in Indigenous Research. International Journal of Critical Indigenous Studies, 3(1), 37-50.

Bradley, D., Noonan, P., Nugent, H., \& Scales, B. (2008). Review of Australian Higher Education Final Report. Retrieved from Canberra: http://www.deewr.gov.au/he_review_finalreport

Charles Darwin University. (2015). Annual Report 2014. Retrieved from Darwin

Frawley, J., Smith, J., \& Larkin, S. (2015). Beyond Bradley and Behrendt: Building a stronger evidencebase about Indigenous pathways and transitions into higher education. Learning Communities: International Journal of Learning in Social Contexts, Special Issue: Indigenous Pathways and Transitions into Higher Education(17). 
Kickett, M. (2011). Examination of how a culturally-appropriate definition of resilience affects the physical and mental health of Aboriginal people. (Doctor of Philosophy), University of Western Australia, Perth

Moreton-Robinson, A., Singh, D., Kolopenuk, J., \& Robinson, A. (2012). Learning The Lessons? PreService Teacher Preparation for Teaching Aboriginal and Torres Strait Islander Students. Retrieved from Brisbane:

Nakata, M. (2007a). The Cultural Interface. The Australian Journal of Indigenous Education, 36(Supplement), 7-14.

Nakata, M. (2007b). Disciplining the Savages: Savaging the Disciplines. Canberra: Aboriginal Studies Press.

Nutton, G., Moss, B., Fraser, J., McKenzie, J., \& Silburn, S. (2012). Recruitment, retention and development of quality educators in very remote NT schools. Prepared for Norhtern Territory Department of Education and Training. Retrieved from Darwin http://ccde.menzies.edu.au/sites/ default/files/documents/Workforce report FINAL dated.pdf

Pechenkina, E., \& Anderson, I. (2011). Background paper on Indigenous Australian Higher Education: Trends, Initiatives and Policy Implications. Retrieved from

Reedy, A., Prescott, D., \& Giles, W. (2011). Cooperative and Work-Integrated Education and Indigenous Peoples. In R. K. Coll \& K. Zegwaard (Eds.), International Hanbook for Cooperative and WorkIntegrated Education. International Perspectives of Theory, Research and Practice (Second Edition ed.). Lowell, MA: World Associationfor Cooperative Education

Reeves, T., Herrington, J., \& Oliver, R. (2005). Design Research: A socially responsible approach to instructional technology research in higher education. Journal of Computing in Higher Education, 16(2), 96-115.

Reeves, T. C., \& McKenney, S. (2012). 7 Things You Should Know About Educational Design Research. Retrieved from https://net.educause.edu/ir/library/pdf/ELI7087.pdf

Rennie, E., Hogan, E., Crouch, A., Gregory, R., \& Thomas, J. (2015). Home internet in remote Indigenous communities summary of findings. Australian Communications Consumer Action Network.

Santoro, N., Reid, J.-A., Crawford, L., \& Simpson, L. (2011). Teaching Indigenous Children: Listening to and learning from Indigenous teachers. Australian Journal of Teacher Education, 36(10), 65-76. doi:10.14221/ajte.2011v36n10.2 